\title{
HYDRODYNAMIC IMPACTS OF TIDAL POWER LAGOONS IN THE BAY OF FUNDY
}

\author{
Julien Cousineau ${ }^{1}$, Ioan Nistor ${ }^{2}$ and Andrew Cornett ${ }^{3}$
}

\begin{abstract}
The Bay of Fundy (BoF) in eastern Canada has long been recognised as one of the world's premier locations for the development of tidal power generating systems, since it has some of the world's largest tidal ranges. Several proposals have been made in recent years to find economical ways to harness the power of these extremely high tides, including constructing one or more tidal power lagoons in the upper part of the Bay. The tidal power lagoon concept involves temporarily storing seawater behind an impoundment dike and generating power by gradually releasing the impounded seawater through conventional low-head hydroelectric turbines. A tidal power lagoon will inherently modify the tides and tidal currents in the vicinity of the lagoon, and possibly induce effects that may be felt throughout the entire BoF and Gulf of Maine. The nature of these hydrodynamic impacts will likely depend on the size of the tidal lagoon, its location, and its method of operation. It is important to have reliable estimates of these potential impacts, since any changes in tidal hydrodynamics caused by a tidal lagoon may upset ecosystems that are well adapted to existing conditions. The scale and character of the potential hydrodynamic impacts due to tidal power lagoons operating in the BoF have not been previously investigated. This paper presents the results of study in which a 2D (depth-averaged) hydrodynamic model based on the TELEMAC modelling system was developed and applied to analyze, predict, and quantify the potential changes in tidal hydrodynamics (water levels, tidal range, circulation patterns and tidal currents) throughout the Bay of Fundy and Gulf of Maine due to the presence of a single tidal lagoon and multiple lagoons operating at various locations in the upper BoF. The sensitivity to changes in lagoon type, size, location, the number of lagoons, and their operating mode was also investigated and established. The final purpose of this novel study is to assist with decisions concerning the development of the vast tidal energy resources available in the Bay of Fundy, Canada.
\end{abstract}

Keywords: Bay of Fundy; tidal lagoon; tidal power; renewable energy; hydrodynamics; numerical model

\section{INTRODUCTION}

The Bay of Fundy (BoF), located on the Atlantic coast of North America, between the Canadian provinces of Nova Scotia and New Brunswick, is renowned for its large tides, which are among the world's largest (Figure 1). The Fundy tides are semi-diurnal; twice each day roughly 115 billion tonnes of seawater flow in and out of the $255 \mathrm{~km}$ long Bay. The tidal range near Burntcoat Head, located in Minas Basin, can exceed $16 \mathrm{~m}$ during spring tides. The natural geometry and bathymetry of the Bay of Fundy are the main factors responsible for producing these very large tides. The BoF, together with Gulf of Maine (GoM), forms a funnel with a natural period of approximately 13 hours, close to the 12.42 hour period of the $\mathrm{M}_{2}$ tidal forcing. The large tides are a result of the near-resonant response of the BoF-GoM system to the $\mathrm{M}_{2}$ tidal forcing (Garrett 1972). Because of the large tidal range and the strong tidal currents that arise in certain locations, the Bay of Fundy has long been recognized as an ideal site for tidal renewable-energy projects.

In the early 1970s, a series of technical and economic assessments were performed to investigate the feasibility and environmental impacts of a potential large-scale tidal barrage in the Bay of Fundy (BFTPRB 1977). From these studies, it has been shown that small changes in the geometry of the Bay, associated with the construction of a tidal barrage, could produce significant changes in tidal amplitudes as far away as Boston. It was concluded that the development of a large-scale tidal barrage was considered potentially hazardous to the surrounding ecosystem and with inadequate funds to start the project, the project was never implemented. Although a large-scale tidal barrage was not constructed, a smaller-scale tidal barrage was completed at Annapolis Royal, Nova Scotia in 1984. The Annapolis Royal tidal barrage remains one of three tidal power plants operating worldwide.

\section{Tidal Power Lagoon Concept}

Presently, there is considerable interest in the idea of implementing tidal power lagoons in the upper Bay of Fundy. The tidal lagoon concept is a more recent approach to tidal power conversion that attempts to solve some of the environmental problems associated with tidal barrages. Rather than blocking off a section of the Bay with a barrage, the tidal lagoon concept involves constructing a circular impoundment structure (a rubble-mound dike or caisson) and a power-house containing sluices and conventional low-head hydroelectric generating equipment, situated a mile or more offshore in an area with shallow depths and high tides. A tidal power lagoon may also be attached to the shore, so that the shoreline forms a part of the impoundment (Figure 2). Although tidal power lagoons are generally thought to be technically feasible, their environmental impacts have not been investigated in detail.

\footnotetext{
${ }^{1}$ Graduate Student, Dept. of Civil Engineering, University of Ottawa, Ottawa, CA, julien.cousineau@gmail.com

${ }^{2}$ Associate Professor, Dept. of Civil Engineering, University of Ottawa, Ottawa, CA, inistor@uottawa.ca

${ }^{3}$ Group Leader, Ocean, Coastal and River Engineering, NRC, Ottawa, CA, andrew.cornett@nrc-cnrc.gc.ca
} 


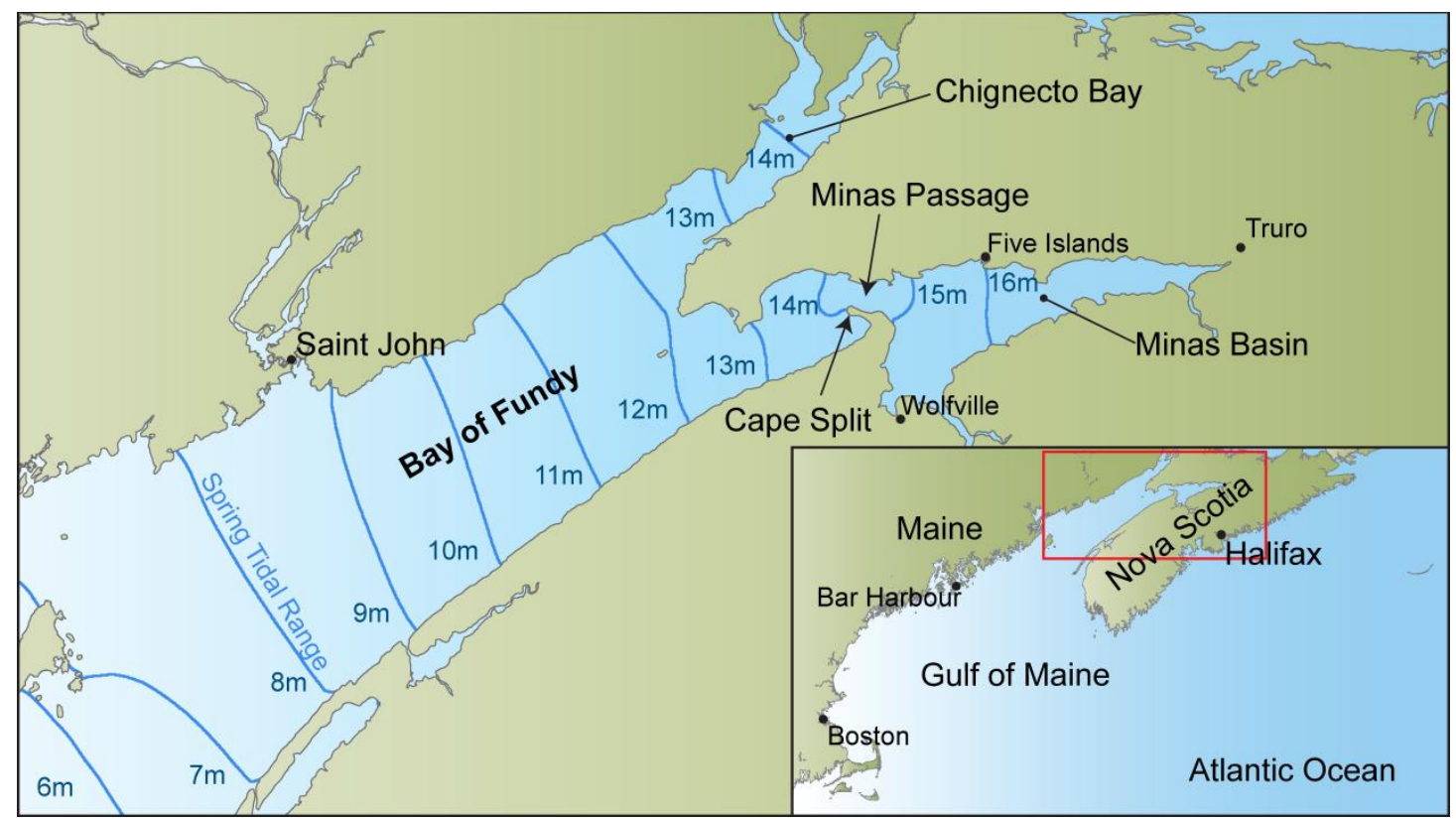

Figure 1. Map of the Gulf of Maine and Bay of Fundy showing Spring tidal range.

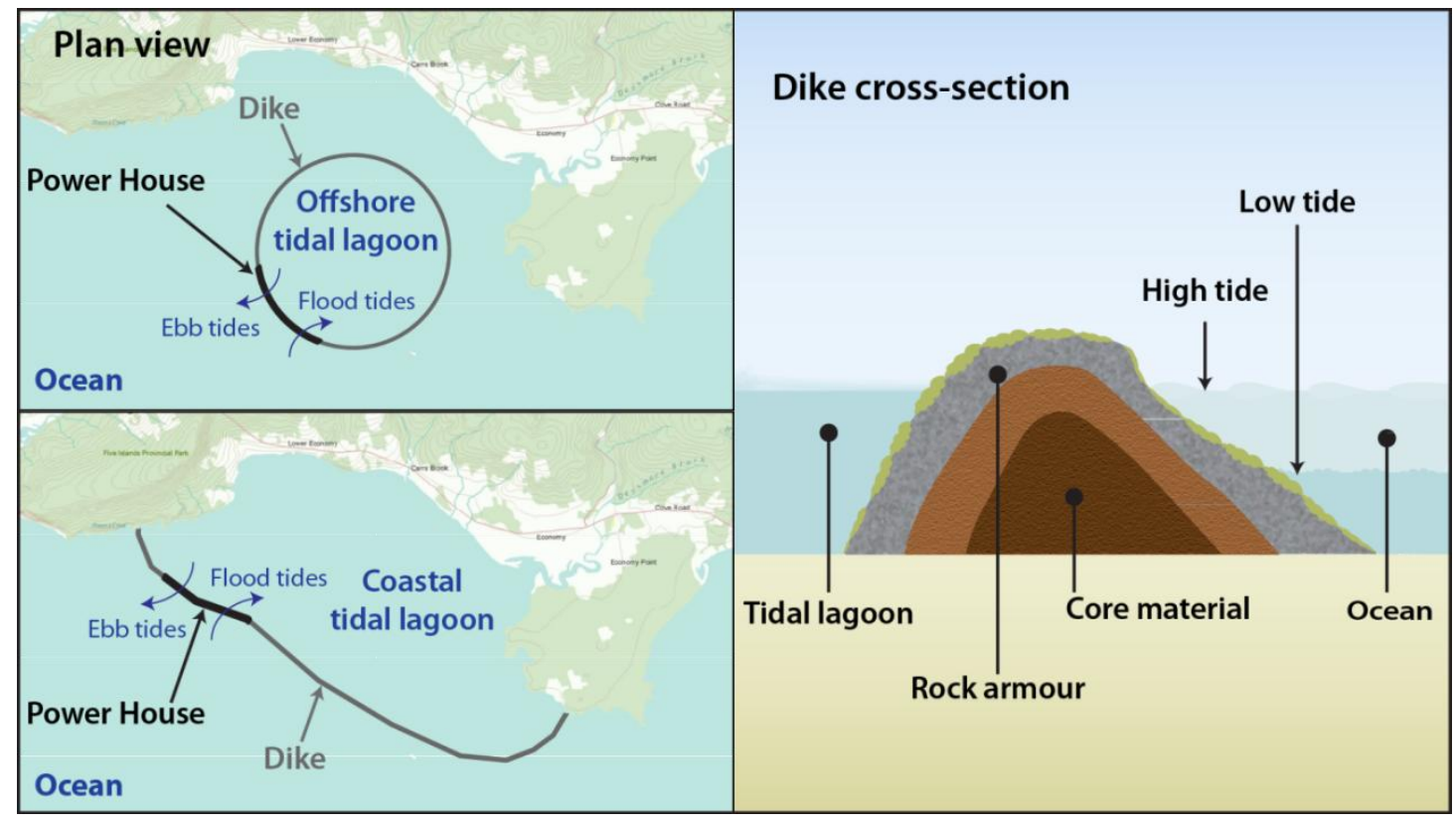

Figure 2. Conceptual layout of offshore and coastal tidal power lagoons.

In 2006, Delta Marine Consultants (DMC) was retained by Tidal Electric Canada (TEC) to assess the feasibility of constructing tidal power lagoons in the upper Bay of Fundy (DMC 2007). DMC proposed constructing a tidal lagoon on the tidal flats along the northern shore of Minas Basin between Five Islands and Economy Point. Various plant layouts were investigated, including lagoons with single and multiple basins and lagoons with direct and rectified flow through the power station. They concluded that a single basin with direct flow through the power station would be most cost efficient for the Minas Basin site. DMC developed conceptual designs for two lagoon types: a) an offshore lagoon comprising a power station and a $12 \mathrm{~km}^{2}$ circular impoundment enclosed by a $11.9 \mathrm{~km}$ long dike detached from the shore; and b) a coastal lagoon comprising a power station and a $24 \mathrm{~km}^{2}$ impoundment formed between a $10.2 \mathrm{~km}$ long dike and the existing shoreline. According to DMC, a $12 \mathrm{~km}^{2}$ offshore lagoon fitted with fourteen 7.5 m diameter bulb turbine generators (up to $20 \mathrm{MW}$ each) and 15 sluice gates $\left(56 \mathrm{~m}^{2}\right.$ area each) would have a peak output of $280 \mathrm{MW}$ and an average power 
output of approximately $124 \mathrm{MW}$. The larger coastal lagoon, equipped with twenty-four $20 \mathrm{MW}$ bulb turbines and 15 sluices, is estimated to have an average power output of approximately $220 \mathrm{MW}$, and peak output of $480 \mathrm{MW}$.

Any large tidal power lagoon operating in the upper BoF will likely modify the tides and tidal currents near the lagoon, and could perhaps create effects that are felt throughout the entire BoF-GoM region. The nature of these hydrodynamic impacts will likely depend on the size of the tidal lagoon, its location, and its method of operation. Changes to the tidal hydrodynamics may also affect the movement of sediments and/or alter natural ecosystems that are presently well adapted to existing conditions.

\section{Previous Investigations}

Several authors have developed numerical models to simulate tidal hydrodynamics in the GoM and BoF over the years. Greenberg (1979) estimated changes in the tidal range throughout the BoF and GoM associated with various proposals to construct large tidal barrages in the upper part of the BoF. Because of the near-resonant state of the existing system, it has been shown that small changes in the geometry of the Bay, associated with the construction of a tidal barrage, could produce significant changes in tidal amplitudes as far away as Boston.

Karsten et al. (2008) applied a three-dimensional model to investigate the energy that could in theory be extracted from the tidal flows at Minas Passage, a $5.5 \mathrm{~km}$ wide channel located at the entrance to Minas Basin in the upper part of the BoF. They showed that the energy that could (in theory) be recovered exceeds the kinetic energy associated with the undisturbed flow through the Passage by a factor of three or more. They also developed relationships between the amount of energy dissipated at the Passage and the change in the tidal range at various locations throughout the BoF and the GoM.

Cornett et al. (2010) developed detailed two- and three-dimensional models of the tidal flows in the BoF and applied these models to delineate and assess the considerable kinetic energy resources around the Bay associated with the energetic tidal currents.

Xia et al. (2010c) and Falconer et al. (2009) have examined the potential hydrodynamic impacts on the Severn Estuary due to several different proposed renewable-energy projects, including a large coastal lagoon. The Severn Estuary is another ideal site for tidal renewable-energy projects, since it has the third highest tidal range in the world, with a spring tide amplitude approaching $7 \mathrm{~m}$. They used a two-dimensional finite volume numerical model and applied it to forecast the hydrodynamic impacts due to several different power projects. They modelled a large coastal lagoon with an area of approximately $86 \mathrm{~km}^{2}$ and an installed capacity of 1,500 MW, and concluded that the lagoon would have little influence on the hydrodynamic processes in the Severn Estuary.

Xia et al. (2010a) examined the impact of constructing a very large tidal barrage across the Severn Estuary. They refined a two-dimensional hydrodynamic model and used the model to simulate the tidal hydrodynamics with and without the barrage. They concluded that discharges, water levels, and tidal currents would all decrease significantly above the barrage. Xia et al. (2010b) also discussed the influence of alternative operating modes on the hydrodynamic impacts of a large tidal barrage across the Severn Estuary. After considering various factors, they conclude that, for efficient electricity generation and reduced flood risk, ebb-generation or bi-directional generation are preferred over floodgeneration.

\section{Present Study Objectives}

Previous studies have suggested that large tidal barrages located in the upper BoF could have important impacts on the tides and tide-related processes in the $\mathrm{BoF}$ and GoM. However, recent studies from the UK suggest a large tidal power lagoon located in the Severn Estuary would have little influence on the hydrodynamic processes in the Estuary. The scale and character of the potential hydrodynamic impacts due to tidal lagoons operating in the upper Bay of Fundy have not been investigated and remain unknown.

This paper presents results from a study undertaken to address this issue. The study uses a numerical model to investigate the changes in hydrodynamics throughout the BoF and GoM due to several hypothetical development scenarios involving the presence of a single tidal lagoon, or multiple lagoons, operating in the upper BoF. The extent of the changes due to different scenarios involving several number, size and location of lagoons, as well as their operating mode is also investigated. The final purpose of this novel study is to assist with decisions concerning the development of the vast tidal energy resources available in the BoF. 


\section{MODEL DEVELOPMENT AND CALIBRATION}

In this study, tidal hydrodynamics in the BoF and GoM have been simulated using a numerical model based on the TELEMAC modelling system, developed by Electricite de France (Hervouet 2007). Most phenomena of importance in free-surface flows can be included in this model, such as the friction on the bed and lateral boundaries, wind stress on the free surface, Coriolis force, turbulence, and density effects. The dynamic wetting and drying of the tidal flats influences the tidal hydrodynamics in the upper part of the Bay, and these processes were included in the TELEMAC-2D simulations.

TELEMAC-2D employs finite-element methods to solve the Saint-Venant equations over a computational domain subject to initial conditions and boundary conditions. Since the computational domain is represented by a flexible unstructured triangular mesh, a higher spatial resolution can be used in areas of special interest and where spatial gradients are large (i.e., near shorelines), while a lower resolution can be used in areas of lesser interest. The Saint-Venant equations can be written as:

$$
\begin{gathered}
\frac{\partial h}{\partial t}+\vec{u} \cdot \vec{\nabla}(h)+h \cdot \operatorname{div}(\vec{u})=S_{h} \\
\frac{\partial u}{\partial t}+\vec{u} \cdot \vec{\nabla}(u)=-g \frac{\partial Z}{\partial x}+S_{x}+\frac{1}{h} \operatorname{div}\left(h v_{t} \vec{\nabla} u\right) \\
\frac{\partial v}{\partial t}+\vec{u} \cdot \vec{\nabla}(v)=-g \frac{\partial Z}{\partial y}+S_{y}+\frac{1}{h} \operatorname{div}\left(h v_{t} \vec{\nabla} v\right)
\end{gathered}
$$

where $h=$ total water depth $(\mathrm{m}) ; x, y=$ horizontal space coordinates $(\mathrm{m}) ; u, v=$ depth-averaged velocities in $x, y$ direction, respectively $(\mathrm{m} / \mathrm{s}) ; g=$ gravity acceleration $\left(\mathrm{m} / \mathrm{s}^{2}\right) ; v_{t}=$ momentum coefficients $\left(\mathrm{m}^{2} / \mathrm{s}\right) ; Z=$ free surface water elevation $(\mathrm{m}) ; t=$ time $(\mathrm{s}) ; S_{h}, S_{x}$ and $S_{y}=$ source term $\left(\mathrm{m} / \mathrm{s}^{2}\right)$. In this study, the effects of bed friction and Coriolis force are included in the source terms. The eddy viscosity was calculated using the Smagorinsky model (Smagorinsky 1963). The wetting and drying of inter-tidal flats was also included in the modelling.

\section{Computational domain}

The computational domain spans a $235,289 \mathrm{~km}^{2}$ area extending from Providence, Rhode Island, to Halifax, Nova Scotia, and it includes the Bay of Fundy and the entire Gulf of Maine (see Figure 3). The offshore boundary was set beyond the edge of the continental shelf so that the model could be used to assess the hydrodynamic impacts along the entire GoM-BoF coastline. In general, smaller elements were used to provide a higher resolution in shallow coastal areas and in the upper Bay of Fundy, while coarser elements were used further away from the coast. Finer elements were also generated along the continental shelf to accurately reflect the bathymetric variability in this region. Several different unstructured model grids were developed for this study, representing both existing conditions without lagoons and hypothetical future conditions with one or more lagoons operating in the upper part of the Bay. The grid of existing conditions consists of 108,993 nodes and 205,148 triangular elements varying in size from $50 \mathrm{~m}$ to $10 \mathrm{~km}$.

The elevation of the seabed was specified at each node. The inter-tidal areas up to the highest astronomical tide (HAT) shoreline were included in the model domain. The elevations were derived from an integration of data from the following sources:

1. Geobase Canadian Digital Elevation Data,

2. USGS National Elevation Dataset,

3. CHS Multibeam Bathymetry,

4. CHS Nautical Charts,

5. NOAA Soundings and Electronic Navigational Charts, and

6. BODC Gridded Bathymetric Chart of the Oceans.

The first two datasets were used to define the elevations within the intertidal zone. Sources (3), (4) and (5) cover the GoM, the BoF and the Nova Scotian continental shelf. Deep ocean areas not covered by datasets (1) - (5) were populated with the BODC bathymetric dataset. The six datasets were originally referenced to different tidal datums and were adjusted to Universal Transverse Mercator North American Datum (NAD) 83 (Zone 19) coordinates in the horizontal plane and referenced to North American Vertical Datum of 1988 (NAVD 88) in the vertical plane. 


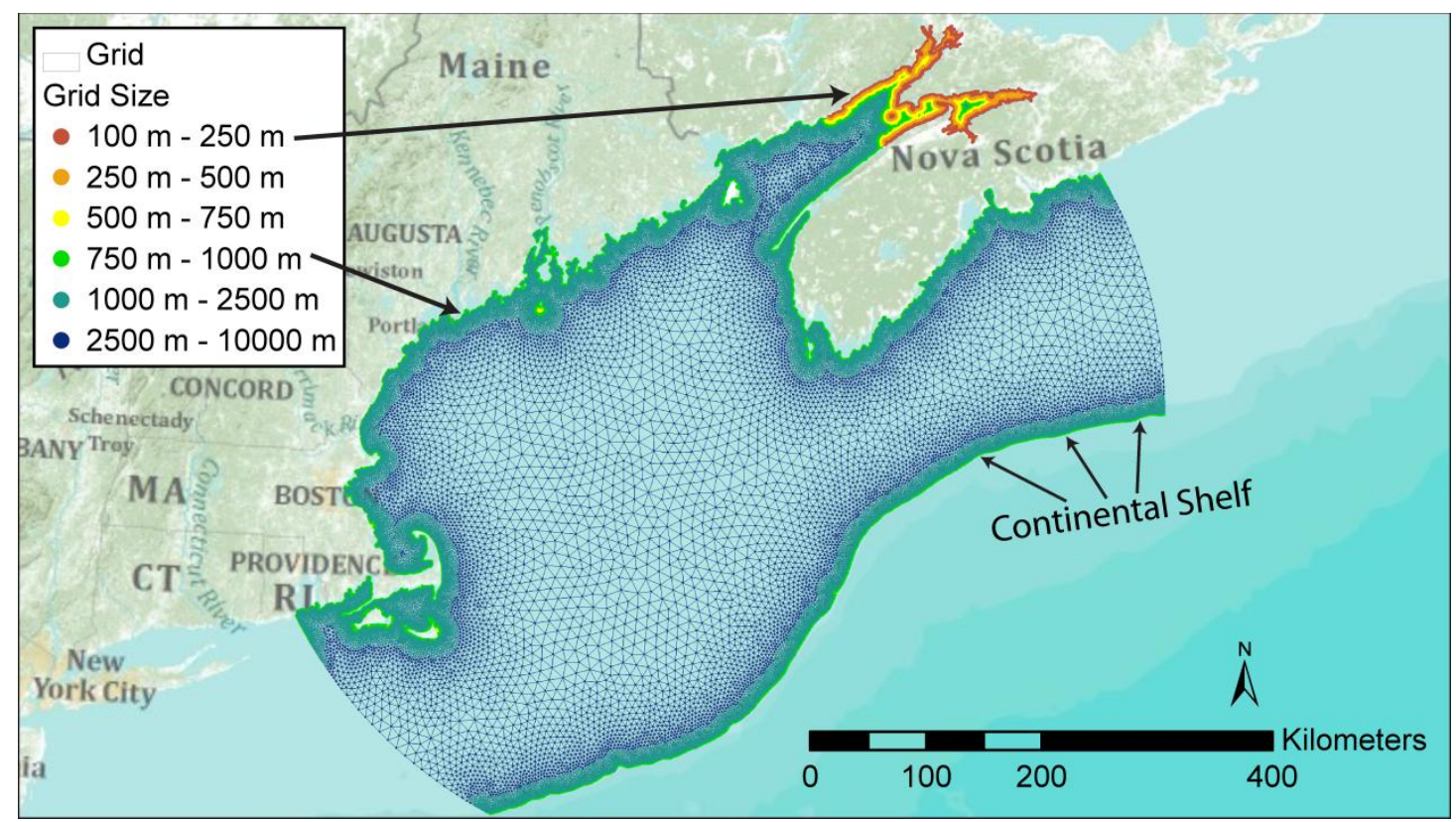

Figure 3. Computational domain and variable mesh resolution.

\section{Boundary Conditions}

Many previous researchers considered only the $\mathrm{M}_{2}$ tidal constituent when studying the hydrodynamic impacts due to tidal power projects in the Bay of Fundy (Greenberg 1979; Sucsy et al. 1992; Greenberg et al. 1997). The $\mathrm{M}_{2}$ constituent is certainly dominant and contributes over $80 \%$ of the total tidal energy in the upper Bay (Zhang et al. 2003). However, in order to achieve realistic predictions, other constituents must be included as well. Hence, the tidal flows due to the $\mathbf{M}_{2}$ constituent and nine other leading constituents have been considered in the present study. Sea surface elevations and initial depth-averaged currents were interpolated along the open ocean boundary using harmonic constants for ten leading constituents $\left(\mathrm{M}_{2}, \mathrm{~N}_{2}, \mathrm{~S}_{2}, \mathrm{~K}_{1}, \mathrm{O}_{1}, \mathrm{~K}_{2}, \mathrm{~L}_{2}, 2 \mathrm{~N}_{2}, \mathrm{NU}_{2}, \mathrm{M}_{4}\right)$. The boundary conditions were calculated from model results produced by a depth-integrated finite-element tidal circulation model (Dupont et al. 2005). This 2-D tidal model has a domain covering the GoM, BoF and part of the Scotian Shelf, and assimilates tidal constituents derived from sea level observations made by the TOPEX-Poseidon altimeter. Freshwater inflows from rivers are insignificant relative to the tidal flows, and were neglected in the present study.

\section{Model Calibration and Validation}

The model was calibrated by adjusting the bottom roughness in different parts of the domain to minimize the error in tide range and time-of-tide between the model's predictions and water level time histories for 150 NOAA/DFO tidal stations distributed throughout the computational domain. For each tidal station, model results were compared to predictions synthesized from harmonic constants established by DFO and NOAA. The same set of 10 constituents $\left(\mathrm{M}_{2}, \mathrm{~N}_{2}, \mathrm{~S}_{2}, \mathrm{~K}_{1}, \mathrm{O}_{1}, \mathrm{~K}_{2}, \mathrm{~L}_{2}, 2 \mathrm{~N}_{2}, \mathrm{NU}_{2}\right.$, $\mathrm{M}_{4}$ ) used to drive the numerical model were also used to generate the target water level time histories for each tidal station. The Strickler's roughness coefficient for different areas was adjusted with values ranging from 20 to 40 in order to minimize the calibration errors throughout the domain. The characteristics of the seabed were taken into consideration when selecting the bottom roughness coefficient for each area. A model time step of ten seconds was chosen to ensure numerical stability. Tides were simulated for periods of 28-days in order to capture two full spring-neap tidal cycles.

The model was first calibrated for the $\mathrm{M}_{2}$ tidal constituent alone, and then for all 10 constituents combined together. The model was calibrated to predict tides over a 28 day period in 2007, carefully selected to include average spring and neap tides. Once successfully calibrated, the model was validated by predicting the tides over 3 different 28 day periods. Figure 4 shows two examples of the results obtained. It can be seen that the numerical model predictions agree very well with astronomical tide projection; both the minimum and maximum water levels, as well as their timing, are predicted with good precision. The depth averaged tidal currents predicted by the model were also compared with available ADCP data for several sites in Minas Passage. The agreement between the measured and 
modelled currents was satisfactory (see Figure 5). Based on these results, it was concluded that the calibrated model is able to predict tidal fluctuations throughout the Bay of Fundy and Gulf of Maine with good accuracy.
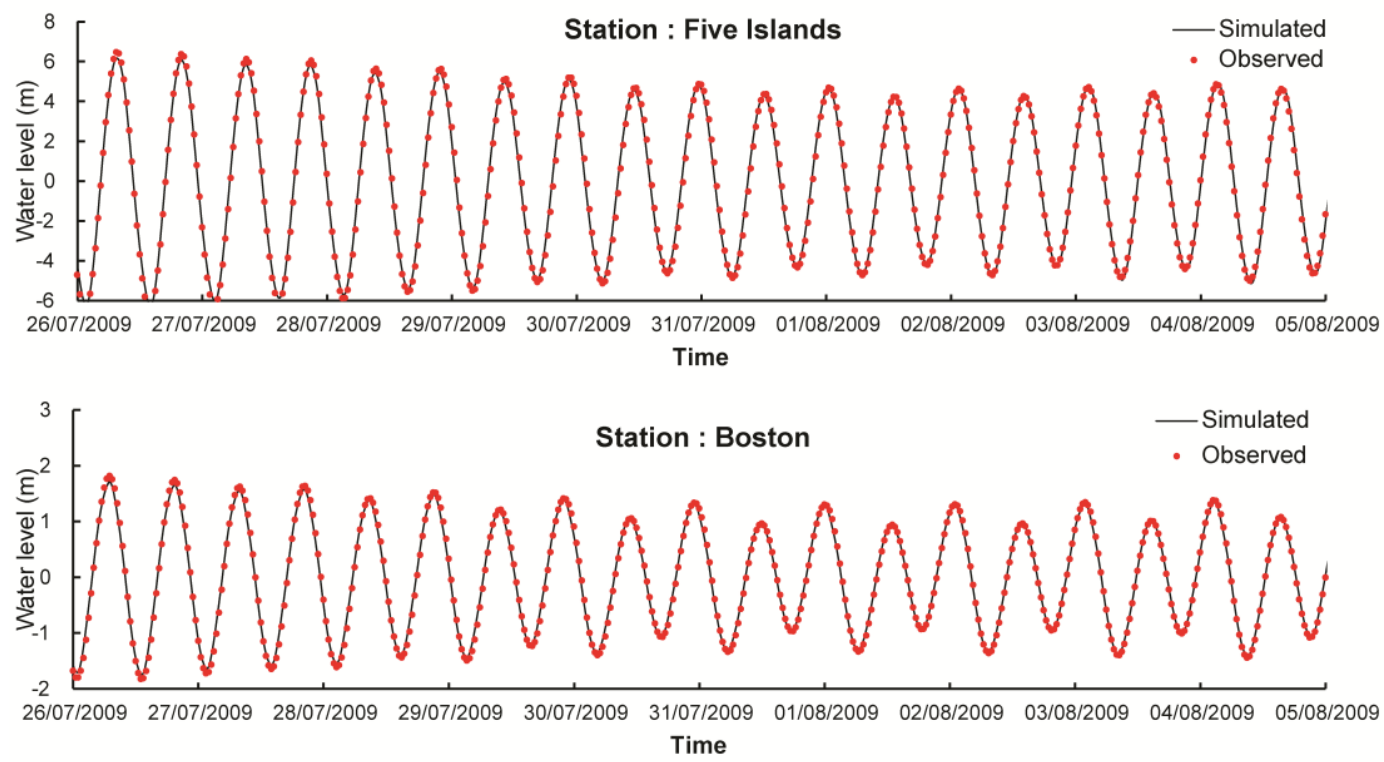

Figure 4. Simulated and observed water levels at two sites.
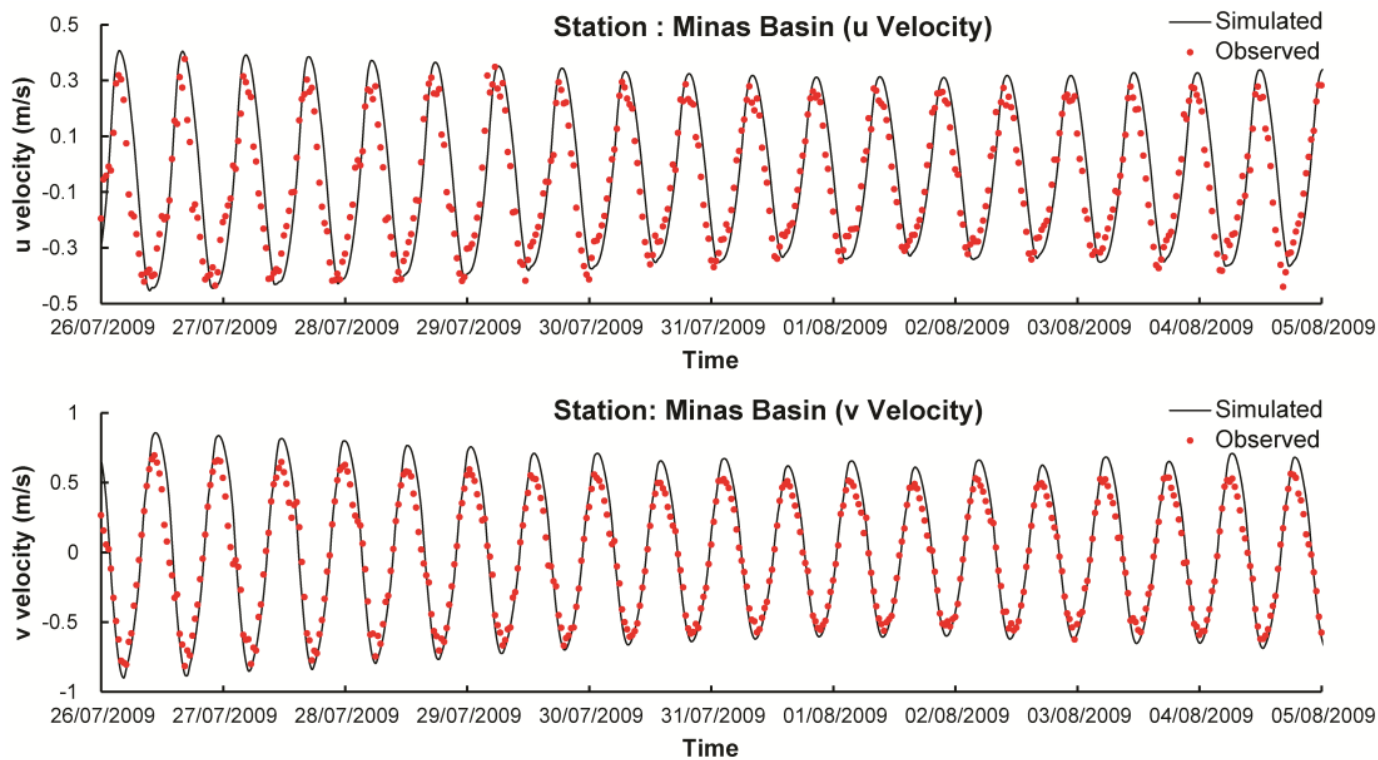

Figure 5. Simulated and observed current velocities ( $u$ and $v$ ) in the Minas Basin.

\section{NUMERICAL SIMULATIONS OF TIDAL POWER LAGOONS}

In addition to the grid of existing conditions, thirteen other grids have been developed to represent various hypothetical scenarios including one or more tidal lagoons. The lagoons are modelled by refining the mesh locally to a resolution of $100 \mathrm{~m}$ along the impoundment dike and around the powerhouse. The mesh is only refined near the lagoon and remains unchanged away from the lagoon. The dike and powerhouse are idealized in the model as vertical sided structures. Similar to Xia et al. (2010b), the interior of the lagoon is modelled as a sub-domain that is disconnected from the main domain outside the lagoon. Multiple pairs or sources and sinks are defined to transfer seawater between the two domains, simulating the flows through the sluices and turbines within the powerhouse. For each lagoon layout, the powerhouse was assumed to have turbines located centrally between the sluices as shown in Figure 6. 


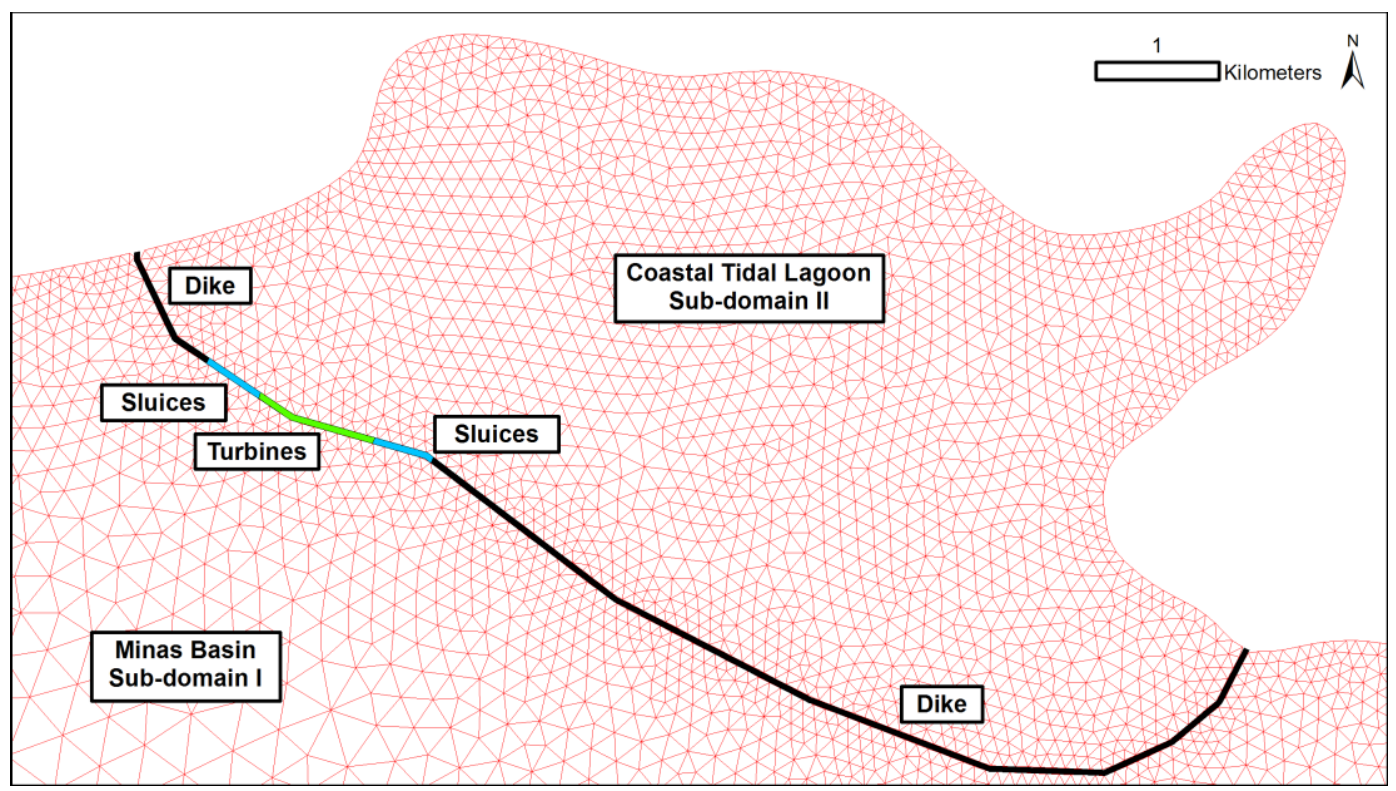

Figure 6. Domain decomposition and grid refinement near the dike.

In these simulations, the discharge through each sluice $Q_{S}$ is given by:

$$
Q_{S}=C_{S} A \sqrt{2 g \Delta H}
$$

where $C_{s}$ is the discharge coefficient for a sluice; $A$ is the cross-sectional area $\left(56 \mathrm{~m}^{2}\right) ; g$ is the acceleration due to gravity $\left(9.806 \mathrm{~m} / \mathrm{s}^{2}\right)$; and $\Delta H$ is the difference in water level across the powerhouse. Although not entirely realistic, a constant discharge coefficient $C_{s}=0.75$ was assumed in this study for simplicity.

The performance of a turbine is often defined as a "hill chart", relating specific discharge, unit speed and efficiency. These charts are based largely on physical and computational fluid dynamics models. However, detailed information on the performance of turbines and generators for tidal power schemes is difficult to obtain due to the desire by manufacturers to maintain confidentiality. An idealized but realistic turbine performance curve has been developed for use in this study, based on data from Baker (1991), which has been adapted to suit the case where the maximum power output to the generator is $20 \mathrm{MW}$, the minimum operating head is $2 \mathrm{~m}$, and the normal operating head is $6 \mathrm{~m}$. The turbine performance curves employed in this study are plotted in Figure 7. It can be seen from the figure that the power increases with increasing water head up to a head of $6 \mathrm{~m}$, and then the power remains constant at $20 \mathrm{MW}$ for heads above $6 \mathrm{~m}$. The discharge through the turbine also reaches its maximum value when the water head is around $6 \mathrm{~m}$, and decreases for both smaller and larger heads. In this study, efficiencies of $90 \%$ on lagoon outflow and $80 \%$ on lagoon inflow were assumed. The turbine performance curves were employed in the numerical simulations to regulate the discharge through each turbine as a function of the water head across the powerhouse, and to compute the power output at each time step.

\section{Operating modes}

Tidal lagoons can be operated in several different modes, including ebb generation, flood generation and two-way generation. Ebb-generation is used at the Annapolis Royal Tidal Generating Station. For ebb-generation, the sluices are used to fill the lagoon during flood tide, and power is generated only during ebb tide. For flood generation, power is generated during flood tide only, and the lagoon is drained during ebb tide. For two-way generation, power is generated when filling the lagoon during the flood tide and when draining the lagoon during the ebb tide. Two-way generation requires that the turbines are operated in both forward and reverse directions. The two-way power generation protocol is depicted in Figure 8. Each tidal cycle comprises eight stages: holding, generating, generating-releasing, releasing, holding, generating, generating-filling, and filling. Each generating stage begins when the head difference across the powerhouse exceeds a minimum value, assumed to be $2 \mathrm{~m}$ in this study; and ends when the head difference falls below a minimum level, also assumed to be $2 \mathrm{~m}$. 


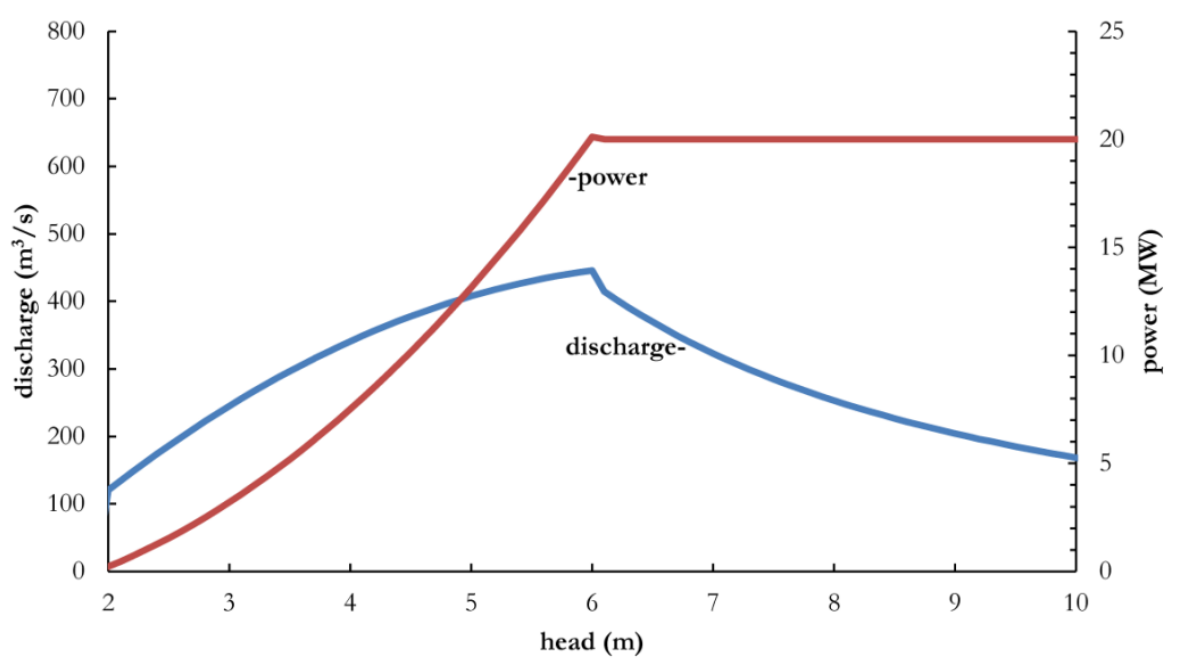

Figure 7. Assumed relationships between head, discharge and power output for 20 MW low-head turbines.

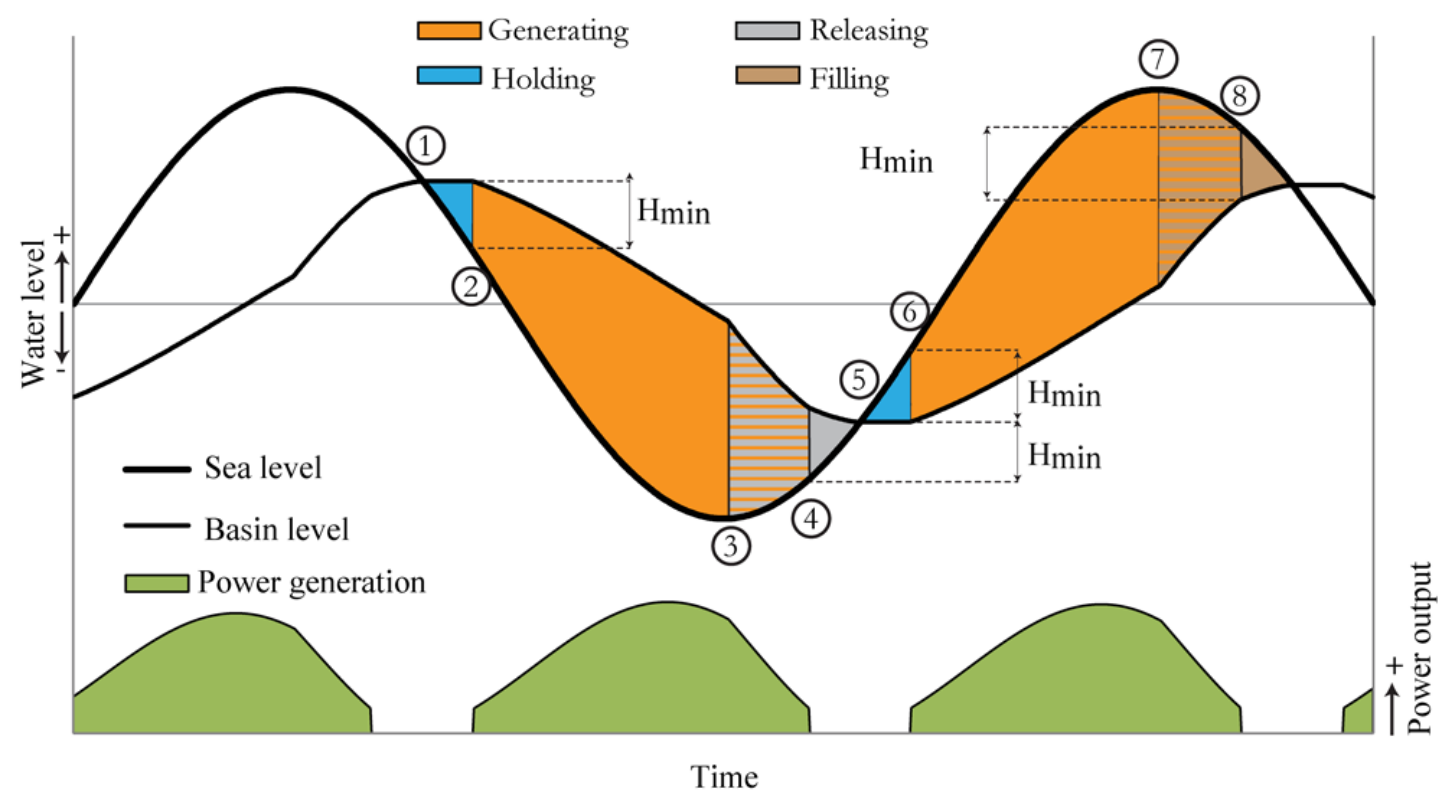

Figure 8. Water levels and power output for the two-way power generation protocol.

\section{MODELLED SCENARIOS}

The numerical model has been used to study the effects that one or more operating tidal lagoons might have on the tidal hydrodynamics in the Bay of Fundy and Gulf of Maine. Nineteen different hypothetical scenarios with one or more tidal power lagoons located in Minas Basin and/or in Chignecto Bay have been modelled. These nineteen scenarios were developed to allow the influence of various parameters to be assessed, including: lagoon type; lagoon location; lagoon size; number of lagoons; and operating protocol. Single lagoons were simulated in some scenarios, while up to six lagoons operating simultaneously were modelled in others. In this way, the relationship between the scale of lagoon development and the scale of potential impacts has been ascertained.

Coastal and offshore tidal lagoons were implemented at six different sites. These sites, named sites A to F, are mapped in Figure 9. Site A, which was proposed by DMC (2007), is located along the northern shore of Minas Basin between Five Islands and Economy Point. Site B is also located along the northern shore of Minas Basin, east of site A near Upper Economy. Site $\mathrm{C}$ is located along the southern shore of Minas Basin near Cambridge. Site D is located along the western shore of Chignecto Bay near Mountville. Site E is located on the eastern shore of Chignecto Bay near Ragged Reef. 
Finally, site F is located on the south-western shore of Chignecto Bay between Alma and Cape Enrage. Several key parameters for the hypothetical development scenarios considered in this study are summarized in Table 1.

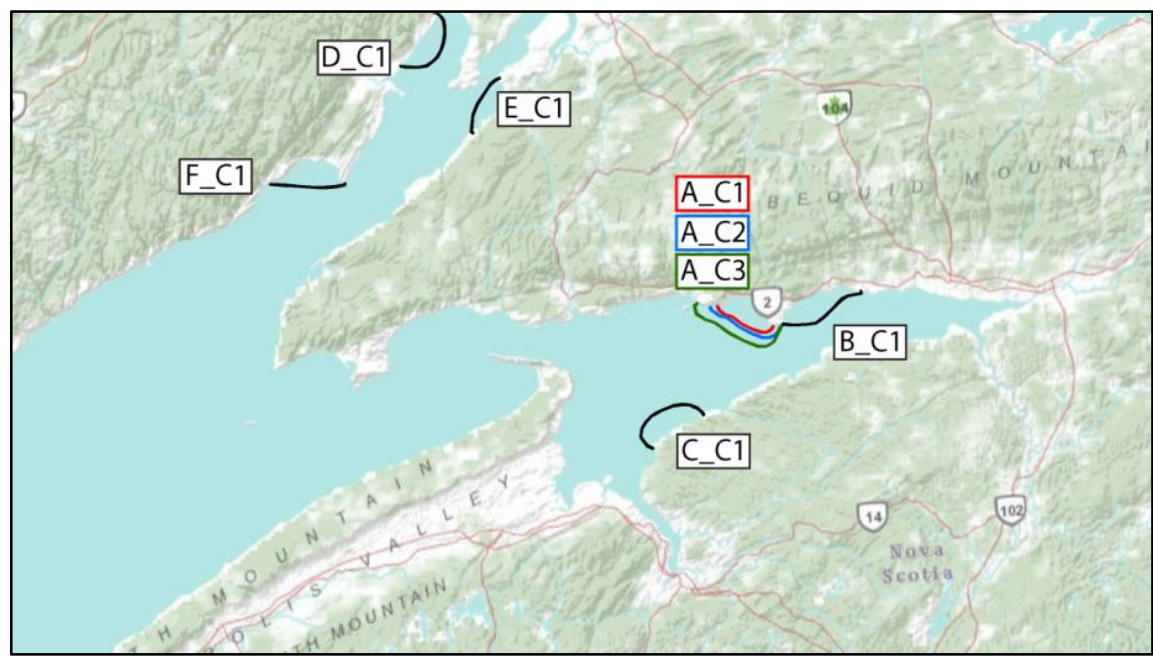

a) Coastal tidal lagoons

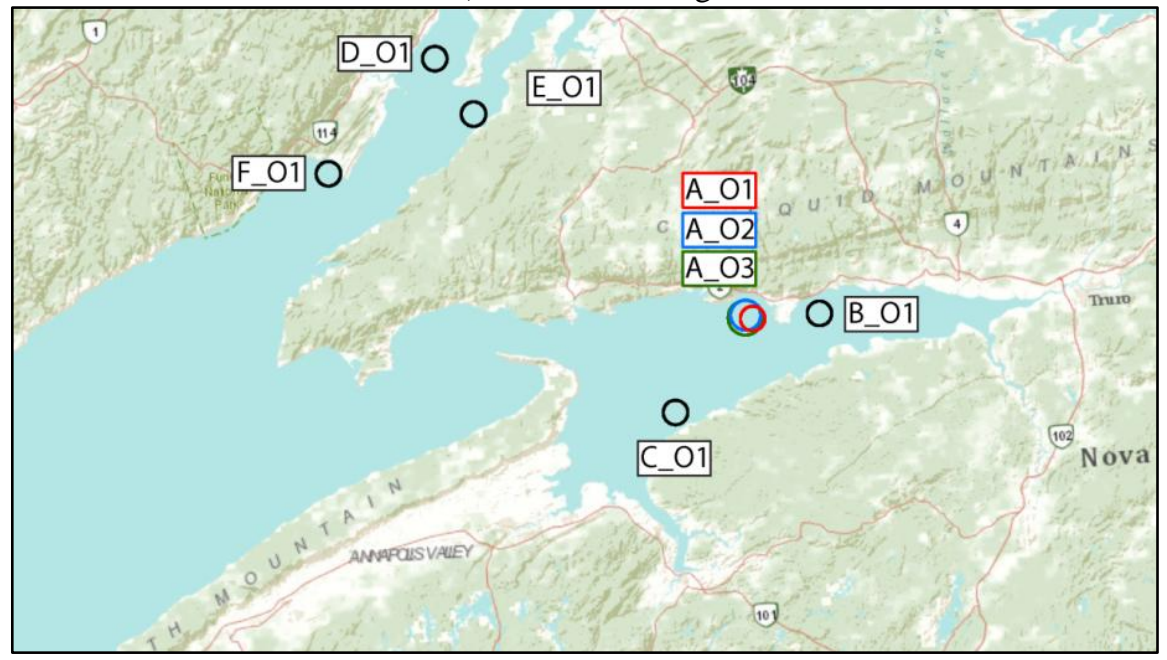

b) Offshore tidal lagoons

Figure 9. Location of hypothetical coastal and offshore tidal lagoons.

The same boundary forcing, developed from 10 harmonic tidal constituents, was employed in every scenario. All the simulations spanned the same 15 day period for which the spring and neap tides were very close to long term average conditions. In addition to modelling hypothetical scenarios, the tidal flows for existing conditions without lagoons were also modelled for the same 15 day period using the same boundary conditions. The changes in tidal hydrodynamics due to each scenario were estimated by differencing the model results for each scenario from those for existing conditions. The impacts of each scenario on water levels, tidal range, circulation patterns and tidal currents have all been assessed in this manner. In this study, the change in tidal range was calculated from the maximum and minimum water levels over the 15 day simulation period.

\section{RESULTS AND DISCUSSION}

\section{Coastal and offshore lagoon at site A: Scenarios S1 and S2}

The tidal power lagoons modelled in scenarios S1 and S2 were developed to replicate the single coastal and offshore lagoons proposed by DMC (2007). The numerical simulations indicate that a $26.7 \mathrm{~km}^{2}$ coastal lagoon at site A (scenario S1) will cause changes in maximum tidal range varying from nil in the eastern part of Minas Basin, up to $+5 \mathrm{~cm}$ at Minas Passage, and ranging from +1 to 
$+4 \mathrm{~cm}$ over a large portion of the BoF and GoM shoreline (see Figure 10a). For the smaller $12 \mathrm{~km}^{2}$ offshore lagoon (scenario S2), except for areas very close to the lagoon, the predicted impact on maximum tidal range is less than $+2 \mathrm{~cm}$ at Minas Passage, and ranges from 0 to $+2 \mathrm{~cm}$ along the shore of the BoF and GoM (see Figure 10b).

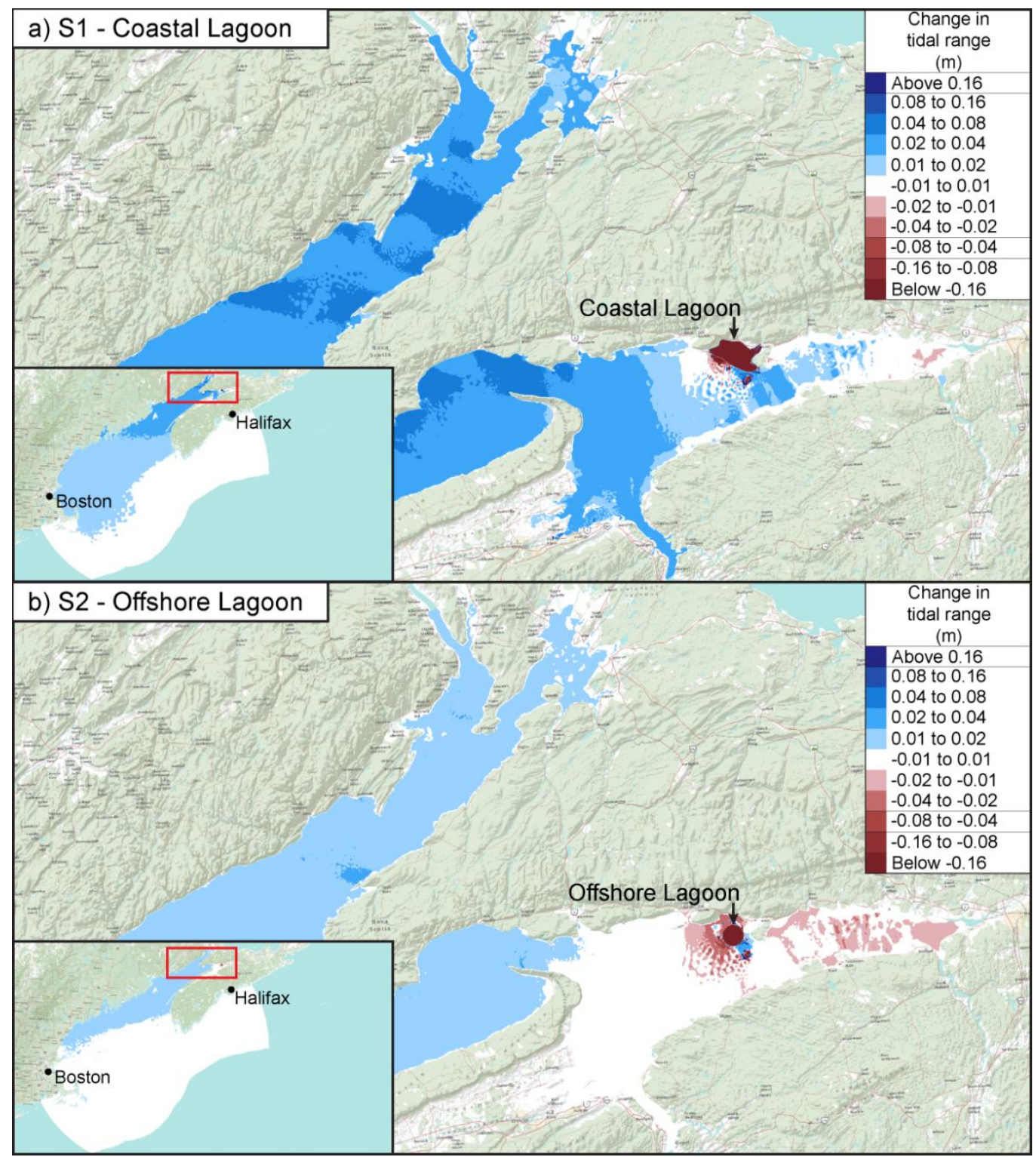

Figure 10. Change in maximum tidal range for single coastal and offshore lagoons at site $A$ (scenario $S 1$ and S2).

Figure 11 shows the predicted change in depth-averaged RMS current velocity $\left(\Delta \mathrm{U}_{\mathrm{RMS}}\right)$ near the coastal and offshore lagoons modelled in scenarios S1 and S2. For the coastal lagoon, significant changes in flow speed $\left(\Delta \mathrm{U}_{\mathrm{RMS}}\right.$ more than $\left.10 \mathrm{~cm} / \mathrm{s}\right)$ are confined to the local area around the lagoon and within the lagoon. It can be seen that, relative to present conditions, flow speeds are significantly greater near the powerhouse outside the lagoon. There is also a large area inside the lagoon where speeds are reduced significantly. At the center of Minas Passage, the RMS current velocity is predicted to decrease by up to $6 \mathrm{~cm} / \mathrm{s}$ for scenario $S 1$ and by up to $3 \mathrm{~cm} / \mathrm{s}$ for scenario $S 2$. The tidal currents in distant locations beyond Minas Passage are virtually unchanged by the lagoons in Minas Basin. 


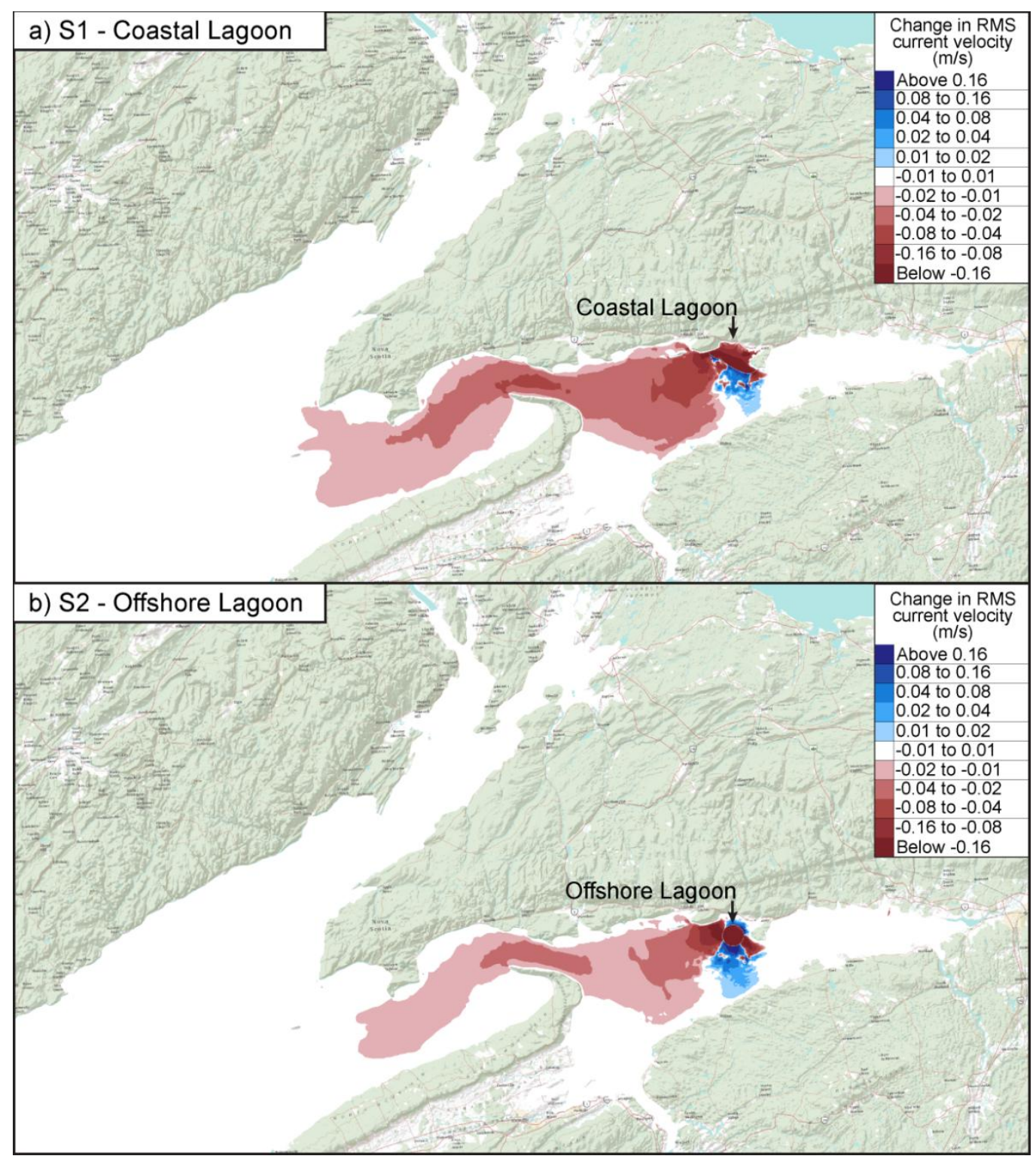

Figure 11. Change in RMS current speed for single coastal and offshore lagoons at site A (scenario S1 and S2).

\section{Summary of hydrodynamic impacts}

Table 1 summarizes, for each of the reference stations identified in Figure 1, the change in maximum tidal range and RMS current speed predicted for each hypothetical development scenario. 


\begin{tabular}{|c|c|c|c|c|c|c|c|c|c|c|c|c|c|c|c|c|c|c|c|c|c|c|c|}
\hline 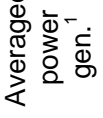 & & 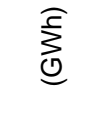 & & $\pi$ & $\stackrel{\Re}{\mathscr{Y}}$ & $\mathbb{N}$ & 8 & $\hat{m}$ & 0 & 0 & 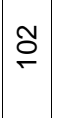 & 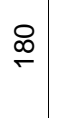 & 尺) & 8 & $\approx$ & 의 & $\stackrel{\Omega}{2}$ & 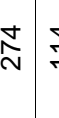 & $\underset{F}{\mp}$ & 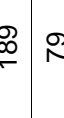 & & 号 & \\
\hline 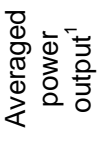 & & $\sum_{\vdots}^{\xi}$ & & ลิ & $\stackrel{\Re}{\stackrel{N}{N}}$ & 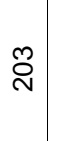 & $\begin{array}{l}\infty \\
\stackrel{0}{0}\end{array}$ & $\stackrel{\infty}{\circ}$ & 0 & 0 & 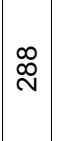 & $\begin{array}{l}\infty \\
i n \\
i n\end{array}$ & $\stackrel{g}{\circ}$ & $\stackrel{\mathscr{\infty}}{\leftarrow}$ & ల్లి & $\stackrel{\widetilde{\infty}}{\stackrel{⿰}{\sim}}$ & 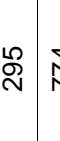 & \begin{tabular}{c}
\multirow{N}{N}{} \\
\end{tabular} & స్లి & 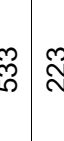 & & : & \\
\hline 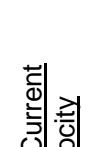 & 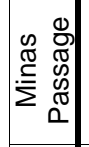 & $\frac{\bar{m}}{\underline{\xi}}$ & 家 & | & 啍 & 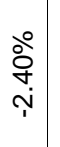 & 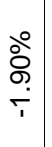 & 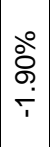 & 竞 & 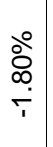 & 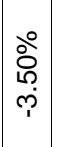 & $\begin{array}{l}\text { o̊ } \\
\vdots \\
\grave{\varphi} \\
1\end{array}$ & 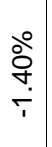 & 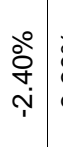 & 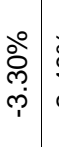 & 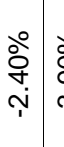 & 仓ें & 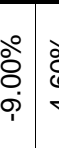 & 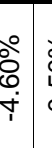 & 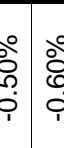 & & ?ִ & \\
\hline$\sum_{\propto}^{\infty}|\vec{s}|$ & 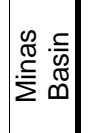 & $\underline{\underline{m}}$ & 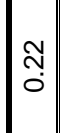 & $\mid$ & 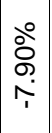 & 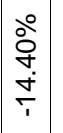 & $\begin{array}{l}\text { O̊̊ } \\
\stackrel{\text { ஸे }}{1}\end{array}$ & 号 & 竞 & 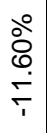 & 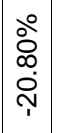 & 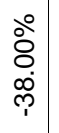 & 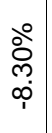 & 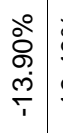 & $\begin{array}{l}0 \\
\stackrel{0}{0} \\
\stackrel{+}{0} \\
\stackrel{0}{1}\end{array}$ & 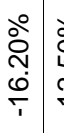 & 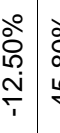 & 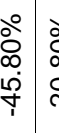 & 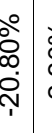 & 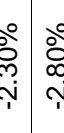 & & bْ & \\
\hline & 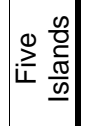 & $\widehat{\xi}$ & 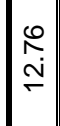 & $\mid$\begin{tabular}{|c}
0 \\
0 \\
0 \\
0 \\
+ \\
+
\end{tabular} & ○̊․ & 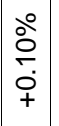 & $\begin{array}{l}\circ \\
\stackrel{0}{0} \\
\dot{0} \\
+\end{array}$ & $\begin{array}{l}\circ \\
\grave{0} \\
\dot{0} \\
+\end{array}$ & $\mid \begin{array}{c}\circ \\
\grave{0} \\
i \\
i\end{array}$ & 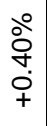 & $\begin{array}{c}0 \\
\stackrel{0}{0} \\
0 \\
+ \\
+\end{array}$ & * & 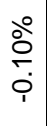 & $\begin{array}{l}\text { o̊ } \\
\stackrel{0}{0} \\
\grave{0}\end{array}$ & 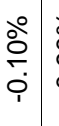 & 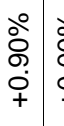 & 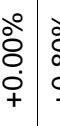 & 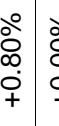 & $\begin{array}{l}\stackrel{0}{0} \\
\vdots \\
0 \\
+\end{array}$ & 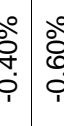 & & $\begin{array}{l}0 \\
\vdots \\
\vdots \\
\vdots \\
\vdots\end{array}$ & \\
\hline & 宂 & $\widehat{\underline{\xi}}$ & $\begin{array}{l}0 \\
\stackrel{0}{0} \\
\stackrel{0}{0}\end{array}$ & $\mid \begin{array}{c}0 \\
0 \\
0 \\
\vdots \\
0 \\
+ \\
\end{array}$ & 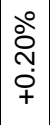 & $\begin{array}{c}\circ \\
\vdots \\
\vdots \\
o \\
+ \\
+\end{array}$ & $\begin{array}{l}\circ \\
\circ \\
\vdots \\
\dot{o} \\
+\end{array}$ & $\begin{array}{c}\circ \\
0 \\
+ \\
0 \\
+ \\
+\end{array}$ & $\begin{array}{l}\circ \\
\stackrel{0}{0} \\
0 \\
+ \\
+\end{array}$ & 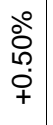 & $\begin{array}{l}\circ \\
0 \\
0 \\
0 \\
+\end{array}$ & $\begin{array}{l}\stackrel{\circ}{\circ} \\
\frac{\dot{\alpha}}{+}\end{array}$ & $\begin{array}{l}\text { ○े } \\
\text { Nे } \\
\text { ○े } \\
+\end{array}$ & $\begin{array}{c}\text { o } \\
\text { Oें } \\
0 \\
+ \\
+\end{array}$ & 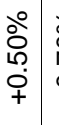 & $\begin{array}{l}\stackrel{0}{\circ} \\
\stackrel{R}{0} \\
\dot{+}\end{array}$ & 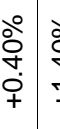 & 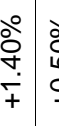 & \begin{tabular}{l|l}
$\circ$ \\
ôे \\
0 \\
0 \\
+
\end{tabular} & 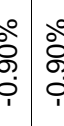 & & 号 & \begin{tabular}{|l|}
$\frac{0}{0}$ \\
0 \\
0 \\
0
\end{tabular} \\
\hline 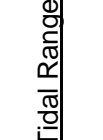 & 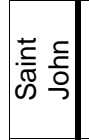 & $\widehat{\underline{\xi}}$ & 胥 & \begin{tabular}{|c|} 
\\
0 \\
0 \\
0 \\
0 \\
+ \\
\end{tabular} & $\begin{array}{l}0 \\
\stackrel{0}{0} \\
\stackrel{0}{o} \\
+\end{array}$ & 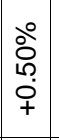 & $\begin{array}{c}\text { O̊. } \\
\text { مُ } \\
0 \\
+ \\
+\end{array}$ & \begin{tabular}{l}
0 \\
\multirow{0}{0}{} \\
0 \\
0 \\
+ \\
+
\end{tabular} & $\begin{array}{c}0 \\
\text { Oें } \\
\\
+ \\
+\end{array}$ & $\begin{array}{l}\text { O̊ } \\
\text { مُ } \\
0 \\
+ \\
\end{array}$ & 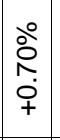 & 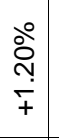 & 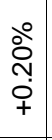 & $\begin{array}{l}\text { o̊ } \\
\text { ờ } \\
\vdots \\
+ \\
+\end{array}$ & $\begin{array}{l}\text { ठ̊ } \\
0 \\
0 \\
\dot{+} \\
+\end{array}$ & 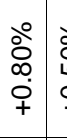 & 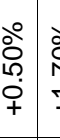 & 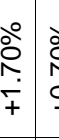 & \begin{tabular}{l|l}
$\circ$ & \\
$\vdots$ & \\
0 & \\
+
\end{tabular} & 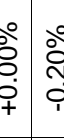 & & $\begin{array}{l}\circ \\
\vdots \\
\vdots \\
+\end{array}$ & $\frac{5}{\frac{5}{\bar{t}}}$ \\
\hline & 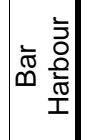 & $\widehat{\xi}$ & $\mid \begin{array}{l}\mathscr{D} \\
\stackrel{p}{p}\end{array}$ & $\mid \begin{array}{c}0 \\
0 \\
0 \\
0 \\
0 \\
+ \\
+\end{array}$ & $\begin{array}{c}\circ \\
\circ \\
0 \\
0 \\
0 \\
+\end{array}$ & $\begin{array}{c}0 \\
\circ \\
0 \\
0 \\
0 \\
+ \\
+\end{array}$ & $\begin{array}{l}0 \\
\vdots \\
\vdots \\
0 \\
+ \\
+\end{array}$ & $\begin{array}{c}0 \\
\vdots \\
0 \\
0 \\
0 \\
+\end{array}$ & $\begin{array}{l}\circ \\
\text { òं } \\
0 \\
0 \\
+ \\
+\end{array}$ & 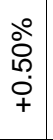 & $\begin{array}{c}\circ \\
\circ \\
\infty \\
0 \\
+ \\
+ \\
\end{array}$ & $\begin{array}{l}\frac{0}{0} \\
\stackrel{0}{+} \\
+\end{array}$ & 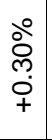 & 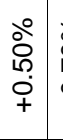 & $\begin{array}{l}0 \\
\grave{0} \\
\vdots \\
\vdots \\
+\end{array}$ & 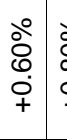 & 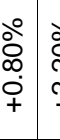 & 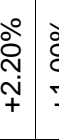 & 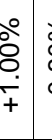 & 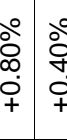 & & 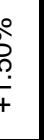 & 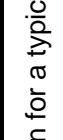 \\
\hline & 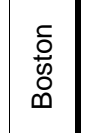 & $\widehat{\underline{\xi}}$ & $\begin{array}{l}\stackrel{0}{\rho} \\
\dot{\rho}\end{array}$ & 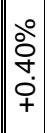 & $\begin{array}{l}\stackrel{0}{\circ} \\
0 \\
0 \\
\dot{+} \\
+\end{array}$ & $\begin{array}{l}0 \\
\vdots \\
\vdots \\
0 \\
0 \\
+\end{array}$ & $\begin{array}{l}\text { O̊. } \\
\text { Dी } \\
0 \\
+ \\
+\end{array}$ & 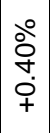 & $\begin{array}{l}\stackrel{0}{0} \\
\text { ôे } \\
0 \\
+ \\
+\end{array}$ & $\begin{array}{l}0 \\
\text { o̊ } \\
\grave{0} \\
+ \\
+\end{array}$ & $\begin{array}{c}\circ \\
\vdots \\
0 \\
0 \\
+ \\
+\end{array}$ & 总 & $\begin{array}{l}\circ \\
\stackrel{0}{0} \\
0 \\
0 \\
+\end{array}$ & $\begin{array}{l}0 \\
\text { ò } \\
\vdots \\
0 \\
+\end{array}$ & \begin{tabular}{l|l}
$\circ$ \\
\\
0 \\
0 \\
+
\end{tabular} & 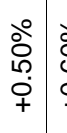 & 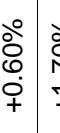 & 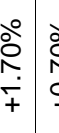 & $\begin{array}{l}\circ \\
\vdots \\
0 \\
0 \\
+\end{array}$ & 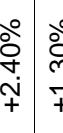 & & $\begin{array}{l}0 \\
\text { ì } \\
+ \\
+\end{array}$ & \begin{tabular}{|l}
$\overline{\bar{T}}$ \\
$\overline{\bar{\sigma}}$ \\
$\overline{\bar{\sigma}}$ \\
$\overline{0}$ \\
\end{tabular} \\
\hline & & 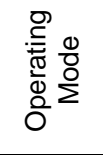 & & 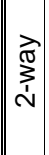 & $\mid \begin{array}{c}\vec{\pi} \\
\substack{3 \\
\sim \\
\sim}\end{array}$ & 痛 & 욤 & $\begin{array}{l}\text { 음 } \\
\frac{8}{4} \\
\end{array}$ & 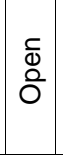 & 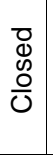 & $\mid \begin{array}{c}\overrightarrow{\mathrm{d}} \\
\stackrel{3}{\sim} \\
\sim\end{array}$ & 䎡 & 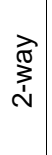 & 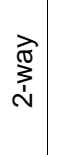 & 恿 & $\begin{array}{l}\text { 蛋 } \\
\text { d. }\end{array}$ & 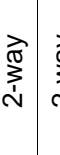 & 离 & ָ̦ & 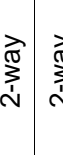 & & & . \\
\hline & & $\stackrel{\infty}{\stackrel{2}{\gtrless}}$ & & $\dot{0}$ & + & $\dot{0}$ & $\dot{0}$ & $\dot{0}$ & $\dot{0}^{\circ}$ & $0^{\circ}$ & $\dot{0}$ & $\dot{0}$ & $0^{\circ}$ & $0^{\circ}$ & $0^{\circ}$ & $\dot{0}$ & $\dot{0}$ & 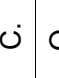 & $0^{\circ}$ & $\dot{0} 0$ & & $\dot{j}$ & 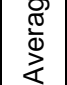 \\
\hline & & 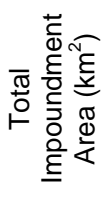 & & 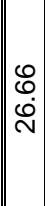 & $\begin{array}{l}\bar{\delta} \\
\stackrel{\mathrm{j}}{\sim}\end{array}$ & $\begin{array}{l}0 \\
\emptyset \\
\stackrel{\leftrightarrow}{ }\end{array}$ & $\begin{array}{l}\stackrel{8}{0} \\
\stackrel{\leftrightarrow}{\sim}\end{array}$ & 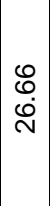 & 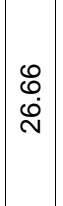 & $\begin{array}{l}\stackrel{8}{0} \\
\stackrel{\leftrightarrow}{\sim}\end{array}$ & ig & \begin{tabular}{|l|} 
\\
0 \\
0 \\
1 \\
10
\end{tabular} & $\begin{array}{l}\bar{\delta} \\
\stackrel{\mathrm{N}}{\sim}\end{array}$ & 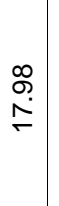 & $\begin{array}{l}\stackrel{g}{o} \\
\underset{\sim}{\sim}\end{array}$ & $\begin{array}{l}\stackrel{\varphi}{\check{j}} \\
\dot{j}\end{array}$ & 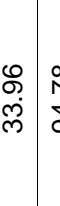 & & $\begin{array}{l}8 \\
\text { c. } \\
\end{array}$ & 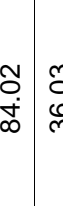 & & & 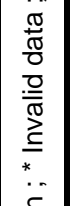 \\
\hline & & $\frac{\bar{D}}{\frac{D}{\omega}}$ & & $<$ & $\ll$ & $\ll$ & $<$ & $<$ & $\ll$ & $\ll$ & $\ll$ & $\ll$ & $\ll$ & $<$ & $\ll b$ & $\infty$ & 0 & 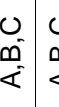 & 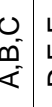 & 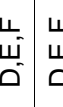 & & | & 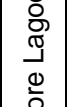 \\
\hline & & 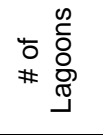 & & - & - & - & - & - & - & - & - & 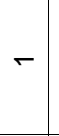 & - & - & - & - & -0 & $\infty$ o & m & $m m$ & & o & $\begin{array}{l}\bar{\sigma} \\
+ \\
\ddot{\delta} \\
\dot{\partial} \\
\end{array}$ \\
\hline & & 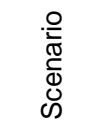 & 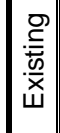 & $\bar{\omega}$ & ஸे & $\mathscr{\infty}$ & ఉ & œ & 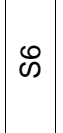 & $\hat{\omega}$ & $\infty$ & ஜ & $\bar{c}$ & $\bar{\omega}$ & $\bar{\omega}$ & $\frac{m}{s}$ & $\bar{\omega}$ & $\frac{\omega n}{\omega}$ & $\frac{6}{\omega}$ & $\bar{\omega} \frac{\alpha}{v}$ & & 5 & $\begin{array}{l}\vec{\pi} \\
\frac{\pi}{0} \\
\tilde{J} \\
0 \\
+ \\
+\end{array}$ \\
\hline
\end{tabular}




\section{Tidal range}

As expected, present simulations suggest that the scale of the changes in tidal hydrodynamics increase with increases in the scale of lagoon development. While multiple lagoons or larger lagoons located in the upper BoF will generate more electrical power, they also induce larger changes in tidal hydrodynamics because they constitute a larger perturbation to a near resonant system.

Figure 12 shows the predicted increase in the tidal range at Boston for the various scenarios considered in the present study. The diamond and round symbols represent scenarios where coastal and offshore tidal lagoons were implemented in the upper Bay of Fundy, respectively. The color of the symbol (blue, green, and red) represents the number of tidal lagoons $(1,3$, and 6 , respectively). For tidal power lagoons in Minas Basin, results reveal a strong linear relationship between the power output and the change in tidal range at Boston. Although lagoons in Chignecto Bay were only considered in two scenarios, these results also suggest a linear relationship between power output and the change in the amplitude of the tides at Boston. Greater power generation is clearly linked to stronger hydrodynamic impacts. Moreover, for equal power output, the impact on the Boston tides due to tidal power lagoons in Chignecto Bay will be roughly double the impact due to lagoons in Minas Basin. In other words, the tides at Boston are roughly twice as sensitive to power generation in Chignecto Bay compared to equivalent power generation in Minas Basin.

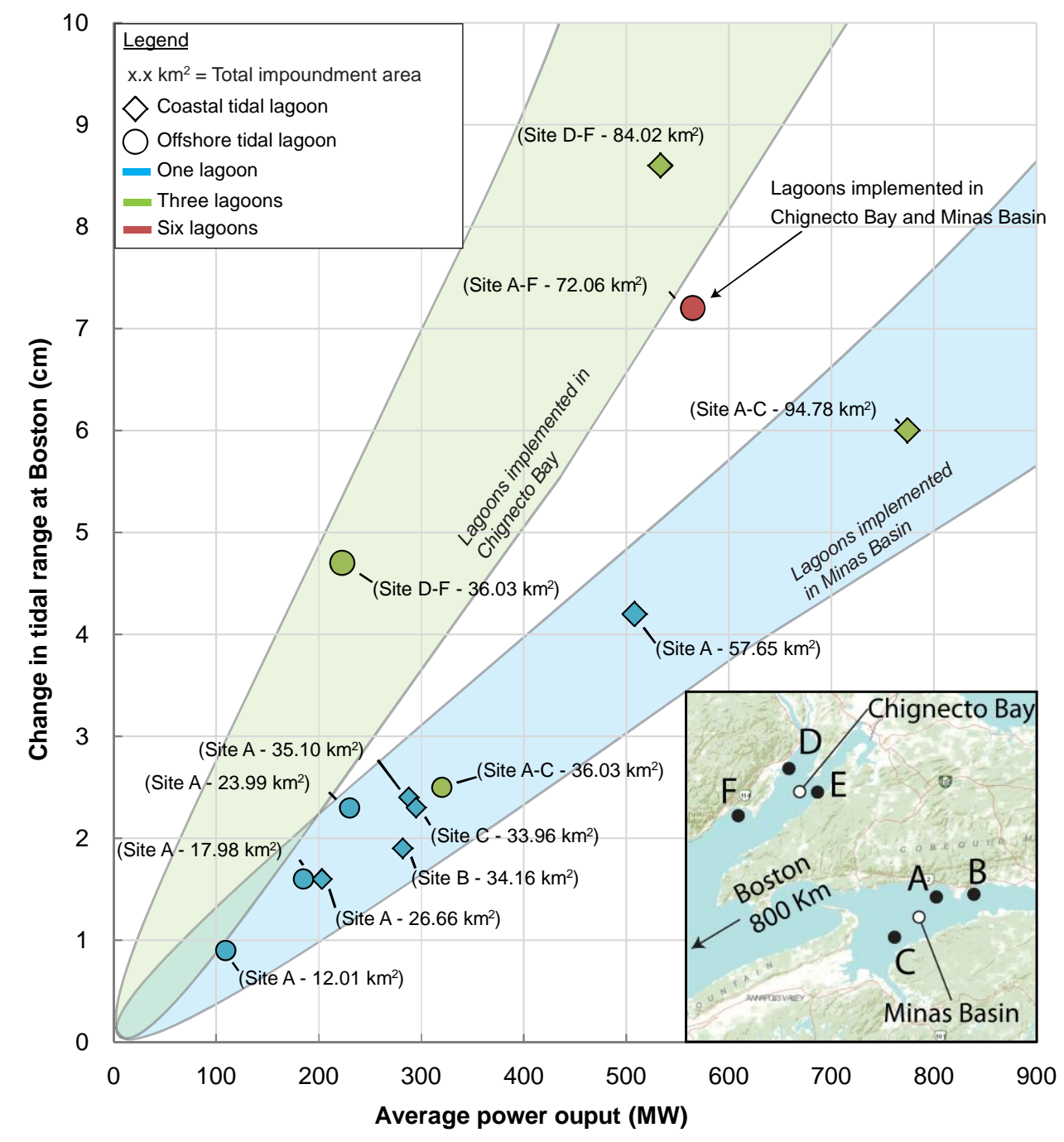

Figure 12. Change in tidal range at Boston due to the implementation of tidal power lagoons. 
Tidal currents

A tidal lagoon will induce local changes in the direction and strength of the tidal currents both within the lagoon and outside it, especially near the powerhouse and along the external perimeter of the impoundment dike. Depending on seabed conditions, scour protection may be required to prevent excessive erosion in these areas. Results show peak velocities near the powerhouse tend to be larger during the ebb than during the flood, due to the shallower water depths outside the lagoon near the end of the ebb phase. Results also show a significant reduction in velocity inside the lagoons. It is possible that fine sediments may tend to accumulate in the lagoons because of these lower velocities. Increased sedimentation is obviously undesirable as this may cause the lagoon to silt up over time. If significant sediment deposition occurs, some intervention may be required to either prevent sediment from settling, or remove the sediment after it has deposited.

Results indicate that tidal currents in remote locations such as the lower Bay of Fundy and Gulf of Maine will remain virtually unchanged, for the hypothetical development scenarios considered in this study. However, depending on the scale of lagoon development in Minas Basin, tidal currents will become notably weaker at the mouth of Minas Basin and particularly in Minas Passage. For example, the results indicate that a single $57.7 \mathrm{~km}^{2}$ coastal lagoon with an average power output of $508 \mathrm{MW}$ operating in Minas Basin will cause a $\sim 6.4 \%$ reduction in the RMS current speed at Minas Passage. This decrease in velocity could lead to a reduction in suspended sediment concentrations and turbidity levels. The positive and negative impacts associated with the environmental and ecological aspects of these changes require further investigation. The speed of the current at Minas Passage is found to be insensitive to lagoon development in Chignecto Bay.

\section{Influence of lagoon operating protocol}

In terms of power output for different operating modes, the mode of flood generation produced the least amount of electricity among the three power generation modes considered. The two-way and ebb generation modes produced similar levels of power output. As for hydrodynamic impacts, the operating mode was found to have some influence on current velocities near the tidal lagoons, particularly within them; however, the operational protocol appears to have little influence on the scale of far-field impacts.

\section{CONCLUSIONS}

This paper presents results from a comprehensive study assessing the hydrodynamic impacts throughout the Bay of Fundy and the Gulf of Maine resulting from tidal power generation by tidal power lagoons located in the upper Bay of Fundy. A detailed two-dimensional (depth-averaged) hydrodynamic model has been developed and applied to investigate the changes in water levels and tidal currents for various hypothetical lagoon development scenarios. The model was successfully calibrated and validated against water level observations for many tide stations throughout the region, and can be used to predict tidal hydrodynamics with good accuracy. Lagoons are simulated by partitioning the model domain into sub-domains, and using source-sink pairs to simulate the exchange of seawater through sluices and turbines. This modelling approach is able to provide a reasonable simulation of the hydrodynamic processes at man-made tidal power lagoons.

The model was subsequently applied to predict tidal hydrodynamics for present conditions without lagoons, and for 19 different hypothetical scenarios with one to six individual lagoons. As expected, the numerical results indicate that any tidal power lagoon will induce some large changes in the pattern and strength of the local tidal currents, particularly near the powerhouse and possibly along portions of the impoundment dike. Numerical results indicate that the changes in water levels and tidal current velocities are largest near the lagoons and generally diminish with increasing distance. Notably, however, some change is predicted throughout the entire Gulf of Maine, even for the smallest development scenario.

The magnitude of hydrodynamic changes was found to be roughly proportional to the scale and extent of the lagoon development, with multiple lagoons and larger lagoons inducing more significant changes. While these changes represent a small fraction of the tidal range, their potential impact on communities and ecosystems warrants further investigation and careful consideration. Hence, without further study, it is difficult to comment at this juncture on whether the potential benefits of tidal power lagoons might outweigh the drawbacks associated with these changes in tidal hydrodynamics.

For the lagoons considered in this study, the power output for a given operating mode was found to be proportional to the surface area of the impoundment. Of the three operational protocols considered in this study, the flood generation mode produced the least electricity, while the two-way and ebb generation modes produced similar levels of power output. The operating mode was found to influence 
local velocities, particularly within the lagoon, but appears to have little influence on the scale of farfield impacts.

A future direction for this research is to investigate the implications of the velocity changes on sediment transport and on the associated morphodynamics of the seabed near and within a lagoon. The new numerical model can also be applied to simulate and assess the hydrodynamic impacts of other tidal energy developments, including tidal barrages and arrays of in-stream turbines.

\section{BIBLIOGRAPHY}

Baker, A. C. 1991. Tidal Power., Peter Peregrinus Ltd., London, United Kingdom.

Bay of Fundy Tidal Power Review Board. 1977. Reassessment of Fundy Tidal Power. Ottawa, Report prepared for the Minister of Supply and Services (Canada), under contract No. 02KX 23384-5207.

Cornett, A., Durand, N., and Serrer, M. 2010. 3-D Modelling and assessment of tidal current resources in the Bay of Fundy. International Conference on Ocean Energy, 3.

Delta Marine Consultants (DMC). 2007. Tidal Power Plant, Bay of Fundy. Technical Feasibility Study.

Dupont, F. and Hannah, C. G. G. D. A. 2005. Modelling the Sea Level of the Upper Bay of Fundy. Atmoshere-Ocean, 43(1):33-47.

Falconer, R., Xia, J., Lin, B., and Ahmadian, R. 2009. The Severn barrage and other tidal energy options:Hydrodynamic and power output modelling. Sci China Ser E-Tech Sci, 52(11):34133424.

Garrett, C. 1972. Tidal resonance in the Bay of Fundy and Gulf of Maine. Nature, 238:441-443.

Greenberg, D. A. 1979. A numerical model investigation of tidal phenomena in the Bay of Fundy and Gulf of Maine. Marine Geodesy, 2(2):161-187.

Greenberg, D., Shore, J., and Shen, Y. 1997. Modelling tidal flows in Passamaquoddy Bay. Proceedings of the Maritime Atlantic Ecozone Science Workshop, 58-64.

Hervouet, J. M. 2007. Hydrodynamics of free-surface flows - modelling with the finite element method.

Karsten, R. H., McMillan, J. M., Lickley, M. J., and Haynes, R. D. 2008. Assessment of tidal current energy in the Minas Passage, Bay of Fundy. Proc. IMechE, 222(Part A: Journal of Power and Energy):493-507.

Smagorinsky, J. 1963. General circulation experiments with the primitive equations I: the basic experiment. Mon. Weather Rev., 91:99-164.

Sucsy, P. V., Pearce, B. R., and G, P. V. 1992. Comparison of Two- and Three-Dimensional Model Simulation of the Effect of a Tidal Barrier on the Gulf of Maine Tides. Journal of Physical Oceanography, 23:1231-1248.

Xia, J., Falconer, R. A., and Lin, B. 2010a. Hydrodynamic impact of a tidal barrage in the Severn Estuary, UK. Renewable Energy, 35:1455-1468.

Xia, J., Falconer, R. A., and Lin, B. 2010b. Impact of different operating modes for a Severn Barrage on the tidal power and flood inundation in the Severn Estuary, UK. Applied Energy, 87:2374-2391.

Xia, J., Falconer, R. A., and Lin, B. 2010c. Impact of different tidal renewable energy projects on the hydrodynamic processes in the Severn Estuary, UK. Ocean Modelling, 32:86-104.

Zhang, A., Wei, E., and Parker, B. B. 2003. Optional estimation of tidal open boundary conditions using predicted tides and adjoint data assimilation technique. Conf. Shelf Res., 1055-1070. 